\title{
Unlocking community capability through promotion of self-help for health: experience from Chakaria, Bangladesh
}

\author{
Abbas Bhuiya ${ }^{1,3^{*}}$, Syed Manzoor Ahmed Hanifi ${ }^{2}$ and Shahidul Hoque ${ }^{2}$
}

\begin{abstract}
Background: People's participation in health, enshrined in the 1978 Alma Ata declaration, seeks to tap into community capability for better health and empowerment. One mechanism to promote participation in health is through participatory action research (PAR) methods. Beginning in 1994, the Bangladeshi research organization ICDDR,B implemented a project "self-help for health," to work with existing rural self-help organizations (SHOs). $\mathrm{SHOs}$ are organizations formed by villagers for their well-being through their own initiatives without external material help. This paper describes the project's implementation, impact, and reflective learnings.

Methods: Following a self-help conceptual framework and PAR, the project focused on building the capacity of SHOs and their members through training on organizational issues, imparting health literacy, and supporting participatory planning and monitoring. Quarterly activity reports and process documentation were the main sources of qualitative data used for this paper, enabling documentation of changes in organizational issues, as well as the number and nature of initiatives taken by the SHOs in the intervention area. Health and demographic surveillance system (HDSS) data from intervention and comparison areas since 1999 allowed assessment of changes in health indicators over time.
\end{abstract}

Results: Villagers and members of the SHOs actively participated in the self-help activities. SHO functionality increased in the intervention area, in terms of improved organizational processes and planned health activities. These included most notably in convening more regular meetings, identifying community needs, developing and implementing action plans, and monitoring progress and impact. Between 1999 and 2015, while decreases in infant mortality and increases in utilization of at least one antenatal care visit occurred similarly in intervention and comparison areas, increases in immunization, skilled birth attendance, facility deliveries and sanitary latrines were substantially more in intervention than comparison areas.

Conclusion: Building community capability by working with pre-existing $\mathrm{SHO}$, encouraging them to place health on their agendas, strengthening their functioning and implementation of health activities led to sustained improvements in utilization of services for over 20 years. Key elements underpinning success include efforts to build and maintain trust, ensuring social inclusion in project activities, and balancing demands for material resources with flexibility to be responsive to community needs.

Keywords: Self-help, Community participation, Community capability, Participatory research, Chakaria, Bangladesh

\footnotetext{
* Correspondence: abbas.bhuiya@gmail.com

${ }^{1}$ Partners in Population and Development, Dhaka, Bangladesh

${ }^{3}$ Formerly of Health Systems and Population Studies Division, International

Centre for Diarrhoeal Disease Research, Bangladesh (icddr,b), Dhaka 1212,

Bangladesh

Full list of author information is available at the end of the article
} 


\section{Background}

Individuals and groups interact, formally and informally, within health systems to ideally improve the health of those living in communities. These interactions facilitated by active community engagement or participation can enhance the utilization of health services $[1,2]$. For example, the success of the Expanded Program on Immunization (EPI) programme in Bangladesh in increasing immunization coverage from $6 \%$ in 1986 to over $75 \%$ in 1991 was only possible with active community participation $[3,4]$. Other examples abound detailing the effects of community participation for improved development outcomes including health, water, sanitation and agriculture $[5,6]$.

One way to facilitate community participation is by using Participatory Rural Appraisal (PRA) [7-9]. The continuum of PRA varies from engaging community members solely in data collection to supporting community use of data collected to understand a phenomenon, such as health seeking behaviour, and design programmes for solving the challenges faced [10]. In most cases of participatory research, community members are considered local experts and researchers attempt to learn from them. In the process, community members may also learn something from the researchers either as groups or individuals. Ideally these exchanges between community members and researchers as outsiders build community capability, but this is not always the case $[5,11]$.

Despite the recognition given to community participation and to PRA for sustained health and development, documentation of such initiatives over the long term and their impact on unlocking community capability is not common in the literature [12]. It is against this background that this paper attempts to document experience from ongoing program efforts to support community participation following PRA starting from the mid-90s in a rural area of Bangladesh. We first describe the local context of Chakaria in rural Bangladesh and the ways in which efforts were designed, implemented and monitored to facilitate community participation and to empower communities to address their own problems. We present outcomes in terms of changes in the organizational practices of self-help organizations (SHOs), as well as the impact of strengthening community capability on health in Chakaria [13].

\section{Methods}

\section{Study area}

Chakaria is located in the southeast coast of the Bay of Bengal. The location of Chakaria has made it very vulnerable to cyclones and tidal waves in addition to regular monsoon flooding. Climate change has heightened the risk of extreme weather events. Administratively, Chakaria is an Upazila (sub-district) with a population of about 474,000 (as of 2011) spread across terrain of which one fifth consists of rivers and canals [14-16]. The main economic activities in the area are agriculture, forestry, and sea-fishing, with shrimp farming recently developed mainly for the international market. Thirty percent of households are landless and about half depend on income from menial labour. Ninety-one percent of the population in Chakaria are Muslim, with the remainder being Hindu or Buddhist. The study site is one of the most religiously conservative areas in Bangladesh, with very low levels of secular education. The literacy rate among population aged 7 years or more is $47.6 \%$ with similar levels for men and women.

In 1994, at the time of starting our efforts, Chakaria Upazila had one 31 bed government hospital located at the Upazila headquarters, two Health and Family Welfare Centres at the union level and two Rural Dispensaries [17]. In 2014, the scenario was quite different: the government hospital had upgraded to 50 beds, there were 11 Health and Family Welfare Centres, and 23 Community Clinics [18], as well as two private clinics.

\section{Self-help approach for unlocking community capability}

The focus of ICDDR,B's efforts to strengthen community capability from 1994 until 2006 through promotion of self-help for health at both individual and collective levels was based on the framework (Fig. 1) proposed by Verhagen and Cebemo [19].

At the individual level, the focus was on raising awareness related to health promotion, prevention and health care seeking. At the collective level, ICDDR,B worked with existing $\mathrm{SHOs}$ to enhance their capacity to tackle community health issues. SHOs are organizations formed by villagers for their well-being through their own initiative without external help. Examples of SHOs include village clubs, youth clubs, profession based associations and cooperatives, and mosque committees. ICDDR,B support to SHOs involved three phases: (1) getting to know the community and building relationships; (2) conducting a needs assessment and designing activities to address the needs identified, and (3) implementation. A summary of the range of PRA techniques used and their purposes are presented in Table 1. Throughout, care was taken to not create a dependency relationship with community members. Hence no material resources were given and no new organizational structures were created. Villagers were involved in these activities right from the start to enhance and build a relationship of mutual trust and to lay the foundation for future processes of community mobilization where they would lead initiatives [20].

The functioning of village health posts, which was an outcome of community initiatives triggered by the ICDDR,B programme, continued by the SHOs for five years from 1999 to 2004 and then had some slackness until 2010 due to reduced support from ICDDR,B because of lack of funding. ICDDR,B inputs to promote 


\section{Framework of engagement with the self-help organizations}

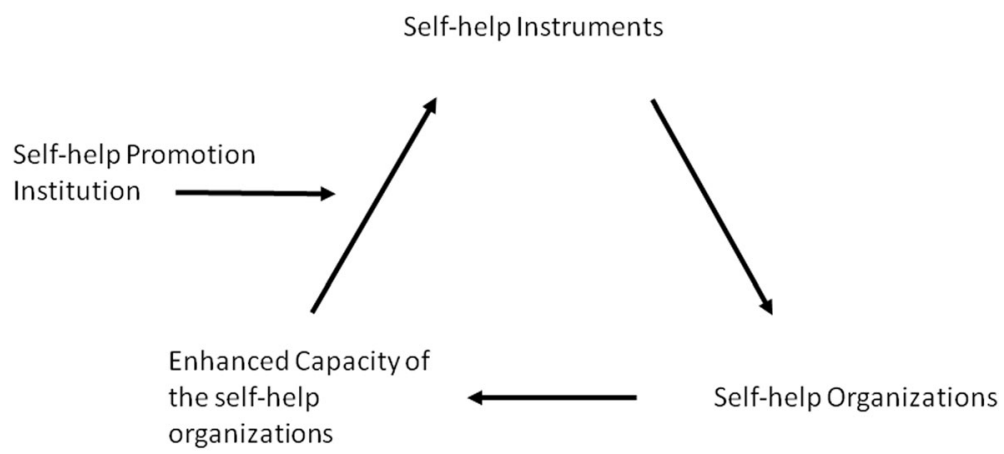

Source: Adopted from Vehagen, 1987 [19]

Fig. 1 Framework of engagement with the self-help organizations

self-help were stopped after 2010 other than implementing a micro-health insurance in the area with village health posts being the point of care.

The ICDDR,B project team, overseen by one project director, was comprised of two groups that worked independently from each other: implementers and those conducting monitoring and evaluation. Some of those involved in monitoring and evaluation were also involved in the Health and Demographic Surveillance System (HDSS). The project team members involved in implementation were trained extensively in PRA methods both at a theoretical level in classes and also through practical experience in communities.

\section{Knowing the community and building confident relationships Transect analysis}

To understand the community and to establish a confident relation with the community, ICDDR,B staff members started with a transect analysis. This involved walking through the villages, getting introduced to people and explaining the purposes of the project in a very informal way. The entry point was talking in common meeting places, such as shops, about common health problems faced by the villagers and ways the villagers manage them. Information about the number of schools, mosques, clubs, other community organizations, and local key and

Table 1 List of PRA techniques used

\begin{tabular}{ll}
\hline PRA tools used & Purpose \\
\hline Transect & Knowing the area, building relationships, and spreading the word about the project. \\
Social Map & $\begin{array}{l}\text { Understanding the social structure, assessing the available institutional resources e.g., SHOs, health facilities. } \\
\text { Seasonal dimension of livelihood, workload, farming, food availability, human diseases, gender-specific income } \\
\text { and expenditure. } \\
\text { Knowing the pattern of villagers' daily activities. Particularly, for looking at relative workloads of different groups } \\
\text { in the community. Identifying suitable time for the availability of the villagers. }\end{array}$ \\
Daily activity clock & $\begin{array}{l}\text { Portraying the importance of various health problems and utilization of health services. } \\
\text { Venn Diagram }\end{array}$ \\
$\begin{array}{l}\text { Billage history } \\
\text { development. }\end{array}$ & $\begin{array}{l}\text { Identifying major health problems, ranking the problems in terms of perceived importance, and identifying } \\
\text { perceived causes, and discussing scientific causes and possible solutions. }\end{array}$ \\
Focus Group Discussion & $\begin{array}{l}\text { Developing a work plan with a time line, assigning who will do what, identifying progress monitoring } \\
\text { indicators. }\end{array}$ \\
People's Participatory Planning & $\begin{array}{l}\text { Monitoring impact of SHO activities, as a routine work, using data collected by the SHO members, and analysed } \\
\text { with the help of the project staff members. }\end{array}$ \\
and Evaluation &
\end{tabular}


resource persons were also gathered during these informal visits.

\section{Participating in social events}

Participation in social events as they occur in communities facilitated outside entry into local social systems, enabling familiarity with community members, and building relationships with trust with them. ICDDR,B staff members participated in social events like, Janaja (funeral prayer for deceased person), sports and cultural functions, Milad (religious gatherings), Juma (Friday) prayers and other important social events.

\section{Participating in government programmes}

Project staff supported community health by participating in government programmes such as EPI sessions and national immunization days. Staff members also participated, on invitation from high schools (6th to 10th grade), in school maternal and child health sessions held in observance of maternal and child health weeks declared by the government. Subsequently, school children spoke highly of the project staff and the sessions to their parents, thereby facilitating further trust building and relationships between project staff and families [20]. This experience also helped project staff realize the importance of school based health education, which was later taken up by ICDDR,B.

\section{Identification of SHOs and key and resource persons}

Traditionally Bangladeshi society has been rich in community organization and initiatives; Chakaria was not an exception to this. A list of self-help organizations along with their contact persons was prepared based on the transect walks, individual and group discussions, and subsequent visits made to the organizations and local key and resource persons. Organizations were selected that had highly representative membership, broad community support, regular meetings, ongoing activities, and resources at their disposal. Attempts were made to keep in touch with organizations and key resource persons that were not selected for active engagement to avoid misunderstanding.

\section{Meetings with SHOs and bringing health onto their agenda}

Project staff started to participate in the routine meetings of selected SHOs and observed the procedures followed in their meetings. None of the organizations initially had health on their agenda. Project staff requested permission from SHO leaders to discuss the major problems people faced. In most cases SHO members identified economic, social and religious well-being as their priority. After intensive discussion between project staff and SHO members, SHO members concluded that good health was also a priority as it was needed for everything, including prayers, education and any activity for making a living.

Discussions with $\mathrm{SHO}$ members indicated that although villagers took initiative to address local issues, they did not perceive a role for themselves in health. Preventive measures, such as immunization and epidemic control, was viewed solely as a government responsibility, while curative care was an individuals' responsibility, managed through consulting with healthcare providers and therefore not perceived as a collective concern [20]. The issue of preventable diseases was raised and discussed, such as the issue of transmission of diarrhea. Villagers were not aware of the causes and routes of transmission of diarrhea. The advantages of preventive health behaviour, and the adverse consequences of sickness on health and economic well-being was further emphasized during subsequent interactions.

Meetings were concluded with the inclusion of health in the SHOs' agendas and an expression of willingness by the organizations to get engaged in health related activities. It was decided that $\mathrm{SHO}$ members would go back and discuss the meeting outcomes with other $\mathrm{SHO}$ members who were not present in the meeting. If they considered that the issues discussed should be addressed, they needed to find ways to incorporate them into their activities. ICDDR,B was willing to provide technical and planning support in this regard, if the organizations desired.

\section{Participatory needs assessment and monitoring Knowing health seeking behaviour}

Wealth ranking and mobility mapping were used to understand people's health seeking behaviour and its relationship with household socioeconomic status. SHO members conducted wealth ranking by classifying households into high, medium and low categories in terms of socioeconomic status. They also drew maps that helped to understand the location of households and nearby health facilities and what kind of health services people resorted to when people became sick in both dry and monsoon seasons. These exercises helped to understand how the utilization of services was linked with household wealth ranking and whether existing health services were accessible or adequate.

\section{People's participatory planning}

While SHOs had the experience of making plans, they were new to participatory planning and required orientation. Project staff first familiarised SHO representatives with the common health issues and problems prevailing in their communities to ensure that participatory planning sessions focussed on health and health related issues. Subsequently SHOs convened meetings to carry 
Table $2 \mathrm{SHO}$ functionality overtime based on project reports

\begin{tabular}{ll}
\hline Before project efforts & After project efforts \\
\hline No specified action plan as an outcome of the meetings & Yearly action plans with time bound monitoring indicators \\
$\begin{array}{l}\text { No systematic monitoring and evaluation system } \\
\text { Issue based fund collection and informal way of holding and managing } \\
\text { funds }\end{array}$ & $\begin{array}{l}\text { Megularing system in place } \\
\text { and formal process of decision for spending money and record keeping }\end{array}$ \\
No plan for leadership and organizational development & Plan for organizational development \& leadership was part of work plan \\
\hline
\end{tabular}

out participatory planning and invited project staff to help facilitate the first couple of sessions.

Participatory planning started with recollecting the past health and development challenges people faced. In most cases the challenges they faced were socioeconomic and developmental in nature. Examples of health challenges included epidemics of cholera, smallpox and outbreak of malaria and other prevalent disease conditions, environmental health issues and harmful practices. This was followed by participatory discussion of root causes of the problems they faced earlier. At the third stage the participants discussed the possible ways to tackle the problems and what resources they had for this purpose. In their opinion communities had human resources (government health workers and village doctors), who could be trained to enhance knowledge and capability on health and development issues, and carry out the health education activities. At the final stage of participatory planning they focused on the future and made short and long term action plans.

\section{Participation of women and the poor}

Analysis of the monitoring data by the project team showed that in most of the participatory planning sessions, only male members participated, and although male villagers from poorer families participated, their voices were not heard. The issue was raised by project facilitators at the participatory planning meetings while presenting data on who participated and who did not. After discussion, SHO members felt the need to support participation by women and poor members in health development activities. They also noted the problem of social exclusion in the school health education programme which did not include children from very poor households because children from poorer families did not attend schools [21]. In contrast in their opinion, mosque-based programs while exclusive to males, did include members from the poor households.

Due to religious and social sentiments, which limited the mobility of women and sustained a highly hierarchical society, it was agreed that women and poorer community members should be included in health activities through a separate process. Health education for women in clusters of households was started with female volunteers. In addition, women's groups formed by development non-governmental organizations (NGOs) for the poorest of the poor were also linked to the SHOs to work collaboratively.

\section{Implementation}

Training of SHO volunteers and dissemination of health messages

Considering the importance of health knowledge, SHOs decided through participatory planning to train $\mathrm{SHO}$ volunteers. Nearly 4,500 volunteers selected by the SHOs were trained and subsequently conducted health awareness sessions throughout the year. Three types of volunteers were identified for training: Male Health Volunteers (831), Female Health Volunteers (1743), School Health Volunteers (1698 both male and female), and Village Health Post Volunteers (177), both male and female. The trained volunteers disseminated health message to respective target populations as indicated below.

- Male Health Volunteers: Disseminated health educational messages to men in male-dominated spaces, such as mosques, tea stalls, clubs, group meetings, village gatherings, gatherings in the neighbourhoods. This health message dissemination was done in an informal manner following a guideline developed by the SHOs with technical support from project staff members.

- Female Health Volunteers: Disseminated health messages using flip charts among women in their neighbourhoods when the women assembled in leisure time.

Table 3 Characteristics of SHOS overtime as measured by project surveys

\begin{tabular}{lcc}
\hline Characteristics & 1994 & 2015 \\
\hline Total number of SHOs in intervention area & 45 & 93 \\
Holding executive committee & $95 \%$ & $100 \%$ \\
Convened meeting regularly & $36 \%$ & $65 \%$ \\
Had written by-laws & $78 \%$ & $67 \%$ \\
Written meeting minutes regularly & $71 \%$ & $65 \%$ \\
Prepared annual financial report & $70 \%$ & $82 \%$ \\
Health matters in agenda in the regular meeting & $0 \%$ & $42 \%$ \\
\hline
\end{tabular}




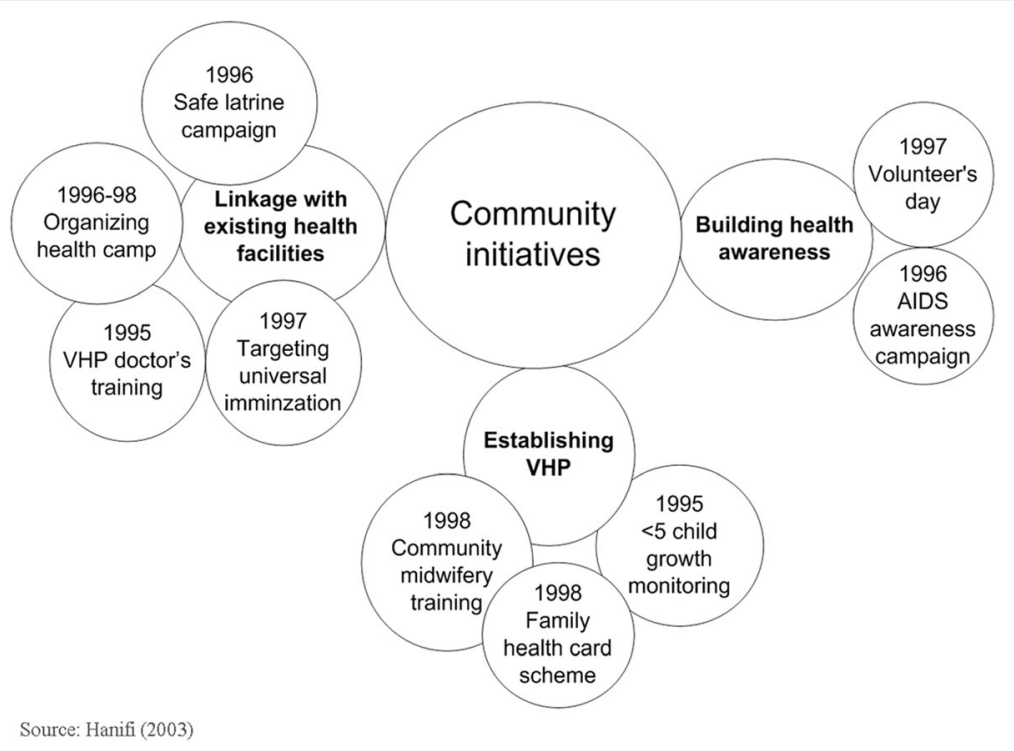

Fig. 2 Some of the health activities undertaken by SHOs

- School Health Volunteers: Students of grade six to 10 disseminated health messages among classmates in schools, playmates in the neighbourhood, family members and other peer group members they found appropriate. This involved role playing wherever appropriate.

- Village Health Post Volunteers: Adult male and female villagers nominated by the SHOs to help manage the operation of the village health posts. This group was formed after the establishment of the village health posts.

After 2 years of health promotion activities the SHO representatives raised the issue that despite all the health education, people still got sick and pregnant women continued to suffer as local health care providers lacked training. SHO members wanted to establish primary care centres in the villages, and also wanted their women trained in community midwifery. While the project did not have any mission to get involved in clinical services, ICDDR,B staff agreed to provide technical assistance by deploying six paramedics, a government recognized cadre of health professionals having a formal diploma in healthcare, for six village posts established by SHOs. The health posts were built with resources mobilized by the SHOs on land donated by a villager. SHOs also identified 15 women from their villages for a 6-month residential course on midwifery with project resources.

\section{Participatory impact monitoring and evaluation}

SHOs established a system to monitor progress and share information between partners, i.e. from project to $\mathrm{SHO}$ representatives and also from $\mathrm{SHOs}$ to project staff. $\mathrm{SHO}$ representatives were oriented to conduct Participatory Impact Monitoring and Evaluation. Volunteers collected information on EPI, sanitary latrines, and other related information decided in consultation with the project team. SHO members compiled the data, initially with help from project staff, and presented it in SHO meetings, where SHO members and villagers participated and analysed the information. This became a regular activity that encouraged SHOs to meet the targets set in their work plans and created an environment of data based decision making.

\section{Study design and study period}

The self-help for health program was implemented by following a quasi-experimental study design with an intervention area (population 125,796 in 1999) and a comparison area (population 40,409 in 1999). Intervention and comparison areas were selected on the basis of similarity of socioeconomic background and from the neighbouring area within the sub district to ensure comparability as much as possible [22]. The comparison area had all the available government and other services available and the project did not interfere with any new services being made available in the comparison area.

\section{Data sources}

Data used in this paper came from surveys carried out in various points in time, project process documents, work plans, project activity reports, and published and unpublished materials. Data for health and demographic outcomes came from the HDSS, which has been in operation since 1999. HDSS, in 1999, included 20,252 and 6,727 randomly chosen households in the intervention and comparison areas respectively [22]. 
Table 4 List of initiatives taken by SHOs and their outcomes, 1994-2015, based on project documentation

\begin{tabular}{|c|c|c|}
\hline Initiatives taken by the SHOs & Actions & Outcome \\
\hline \multicolumn{3}{|l|}{ 1994-2003 } \\
\hline Diarrhoea Epidemic Control & Pushed the local authority to control the epidemic & $\begin{array}{l}\text { Epidemic was controlled; permanent oral rehydration } \\
\text { treatment depot established; SHOs gained confidence } \\
\text { in collective action }\end{array}$ \\
\hline $\begin{array}{l}\text { Campaign for Promotion of } \\
\text { Sanitary Latrines }\end{array}$ & House to house campaign to setup sanitary latrines & $\begin{array}{l}\text { Increase ownership of sanitary latrines; reduced } \\
\text { incidents of related disease; market based latrine } \\
\text { production unit established }\end{array}$ \\
\hline $\begin{array}{l}\text { Campaign to promote hand } \\
\text { washing }\end{array}$ & $\begin{array}{l}\text { SHO members campaigned for proper hand washing } \\
\text { after defecation and before meals }\end{array}$ & $\begin{array}{l}90 \% \text { of households found using ashes or soap; } \\
\text { diarrhoea and other related disease reduced; } \\
\text { continued healthy practices. }\end{array}$ \\
\hline $\begin{array}{l}\text { Campaign to promote practice } \\
\text { of covering food }\end{array}$ & $\begin{array}{l}\text { Traders at the markets were pushed not to sell } \\
\text { unhygienic foods and to cover food after preparation }\end{array}$ & $\begin{array}{l}\text { Foods were seen covered at shops; reduced selling of } \\
\text { unsafe food items; established social responsibility }\end{array}$ \\
\hline Union Health Committee & $\begin{array}{l}\text { Formed a coordination body comprising representatives } \\
\text { from all SHOs in a union }\end{array}$ & $\begin{array}{l}\text { Coordination of all health and development activities } \\
\text { at union level }\end{array}$ \\
\hline Village Health Posts [24] & $\begin{array}{l}\text { SHOs and Union committees established } 7 \text { Village } \\
\text { Health Posts to supplement public health services with } \\
\text { their own resources }\end{array}$ & $\begin{array}{l}\text { Village Health Posts were sustained for long time } \\
\text { (1998-2016); became a community focal point for } \\
\text { health services and social activities. }\end{array}$ \\
\hline Family health card scheme & A low cost family health card scheme initiated & $\begin{array}{l}\text { People were getting benefit from the scheme; } 6 \% \text { of } \\
\text { households enrolled; The scheme later was developed } \\
\text { into micro-health insurance. }\end{array}$ \\
\hline Fund for poor people & $\begin{array}{l}\text { SHO members felt need to have fund to help the poor, } \\
\text { they raise a fund through contribution from people } \\
\text { interested to donate }\end{array}$ & $\begin{array}{l}\text { Poor people getting help from the fund for health and } \\
\text { other needs }\end{array}$ \\
\hline $\begin{array}{l}\text { Health facility monitoring and } \\
\text { utilization }\end{array}$ & $\begin{array}{l}\text { SHOs established a system to monitor government and } \\
\text { non-government health facilities }\end{array}$ & $\begin{array}{l}\text { The facilities were monitored regularly; utilization of } \\
\text { the facilities ensured; linkage with Government of } \\
\text { Bangladesh authorities and committees established }\end{array}$ \\
\hline Health camps & $\begin{array}{l}\text { Health camps were regularly organized by SHOsNillage } \\
\text { Health Post committees for treatment }\end{array}$ & $\begin{array}{l}\text { Ear Nose and Throat, Circumcisions and other special } \\
\text { camps were organized regularly }\end{array}$ \\
\hline $\begin{array}{l}\text { Traditional Birth Attendants' } \\
\text { (TBAs) Training }\end{array}$ & $\begin{array}{l}\text { Training for TBAs were organized by the SHOs and } \\
\text { supervision provided in the form of refresher training } \\
\text { and advice from project physicians }\end{array}$ & $\begin{array}{l}\text { More than } 50 \text { TBAs trained by a hospital near Dhaka, } \\
\text { the capital of Bangladesh. Fee and travel costs were } \\
\text { provided by the project. }\end{array}$ \\
\hline Bed net program [25] & $\begin{array}{l}\text { With government help the bed net program was } \\
\text { initiated }\end{array}$ & $\begin{array}{l}\text { Malaria incident decreased; program run by national } \\
\text { NGOs based on SHO experience }\end{array}$ \\
\hline Training village doctors & $\begin{array}{l}\text { Committees felt the need to train village doctors. SHOs } \\
\text { arranged financial assistance to train village doctors from } \\
\text { Upazila Health Complex }\end{array}$ & $\begin{array}{l}\text { Village doctors were actively giving services; regular } \\
\text { training uptakes by ICDDR,B as part of other program. }\end{array}$ \\
\hline $\begin{array}{l}\text { Training of women as skilled } \\
\text { birth attendant (SBA) [26] }\end{array}$ & $\begin{array}{l}\text { Community demand skilled personnel for assisting } \\
\text { deliveries }\end{array}$ & $\begin{array}{l}14 \text { were trained as community midwives; they are still } \\
\text { giving services the community }\end{array}$ \\
\hline AIDS Awareness Campaign [27] & SHO volunteers carried out the campaign & $\begin{array}{l}\text { Increase of knowledge reported and disseminated as } \\
\text { per ICDDR,B records }\end{array}$ \\
\hline \multicolumn{3}{|l|}{ 2004-2015 } \\
\hline $\begin{array}{l}\text { Running the village health } \\
\text { posts in the absence external } \\
\text { financial support }\end{array}$ & $\begin{array}{l}\text { SHOs kept the village health posts established earlier } \\
\text { running by allowing the community midwives and } \\
\text { trained village doctors to provide services from them. }\end{array}$ & $\begin{array}{l}\text { Village health posts continued to be the place of } \\
\text { lowest primary healthcare for the villagers. }\end{array}$ \\
\hline $\begin{array}{l}\text { Promoting and supporting the } \\
\text { community midwives trained } \\
\text { during the earlier phase }\end{array}$ & $\begin{array}{l}\text { Community midwives got a room at the village health } \\
\text { posts to render their services regularly }\end{array}$ & $\begin{array}{l}\text { Pregnant women are getting benefits from the } \\
\text { midwife services }\end{array}$ \\
\hline $\begin{array}{l}\text { Promoting and supporting the } \\
\text { trained village doctors [28] }\end{array}$ & $\begin{array}{l}\text { Trained village doctors were involved in services of } \\
\text { village health posts }\end{array}$ & $\begin{array}{l}\text { Trained village doctors promoting telemedicine } \\
\text { services }\end{array}$ \\
\hline $\begin{array}{l}\text { Supporting and promoting a } \\
\text { voluntary micro-health } \\
\text { insurance programme }\end{array}$ & $\begin{array}{l}\text { Micro-health insurance services were running from the } \\
\text { village health posts and the committees is in steering } \\
\text { role }\end{array}$ & People enrolling into the scheme \\
\hline
\end{tabular}




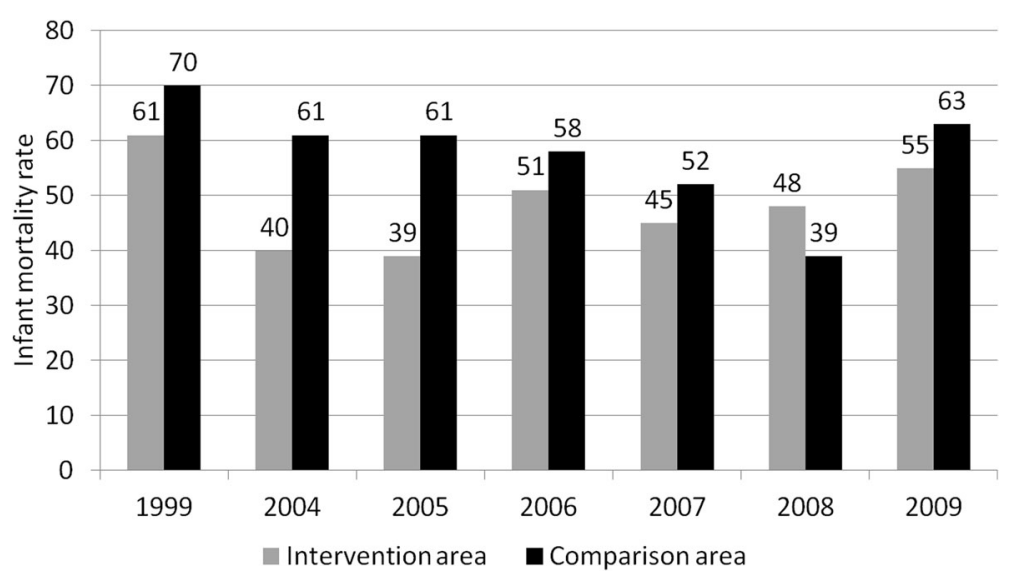

Fig. 3 Infant mortality rate by area

The project implementation design allowed an assessment of long-term effects of self-help approach on community initiatives and responses post 2003 up to 2015. All findings were first shared with the representatives of the SHOs in their monthly meetings.

\section{Results}

\section{Change in the organizational management practices}

Based on the organizational capacity building activities offered by the project, SHOs were able to strengthen their internal organizational management and also how they planned and undertook activities (Tables 2 and 3). Over time, the SHO leadership not only appreciated the value of formalising and systematizing their organizational functioning, but these processes also earned them further confidence from community members.

As detailed in Table 3, the numbers of SHOs doubled between 1994 and 2015 with 51 new SHOs formed. We are not able to determine whether this increase was due to the project or due to a secular trend. Among the 45 organizations listed in 1994, 11 stopped their activities due to various reasons, which included migration of a critical executive committee member and/or merger with other organizations. While most of the organizational characteristics show improvement over time, the proportion of SHOs having written by-laws and regular meeting minutes decreased slightly, although the absolute numbers increased over time. Of note, none of the SHOs had health on their agenda in 1994, but in 2015, 42 \% of SHOs reported that their agenda included health.

Health initiatives by the SHOs and community members Some of the major health initiatives undertaken by SHOs and community members during 1994-2003 and post 2003 are detailed in Table 4 and in Fig. 2 (adapted from Hanifi [23]).

\section{Health outcomes and healthcare utilization}

The self-help for health project aimed to improve the health status of the villagers by increasing collective health promotional actions and utilization of modern healthcare

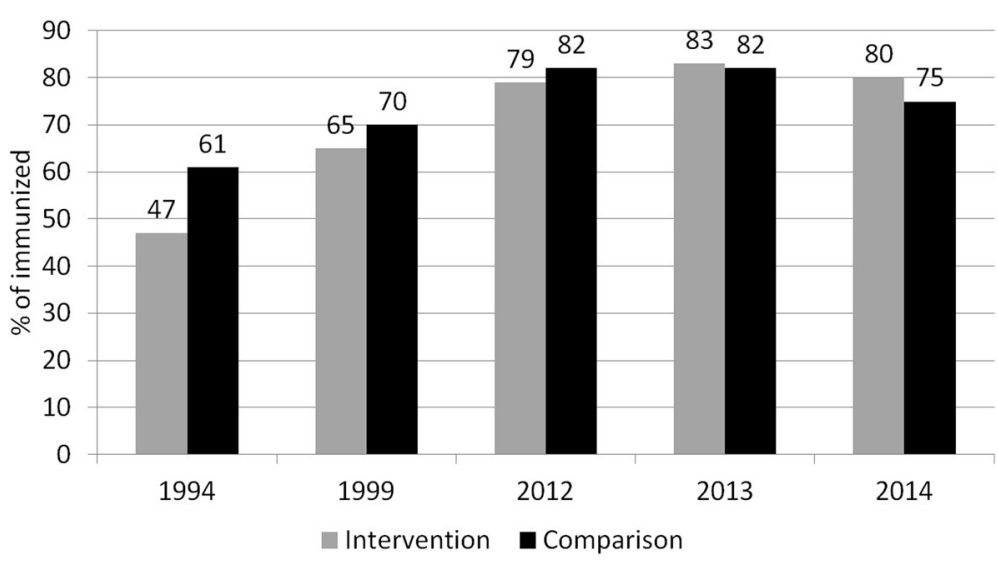

Fig. 4 Percentage of children received five routine vaccines (BCG, DTP1-3, Measles vaccine) 


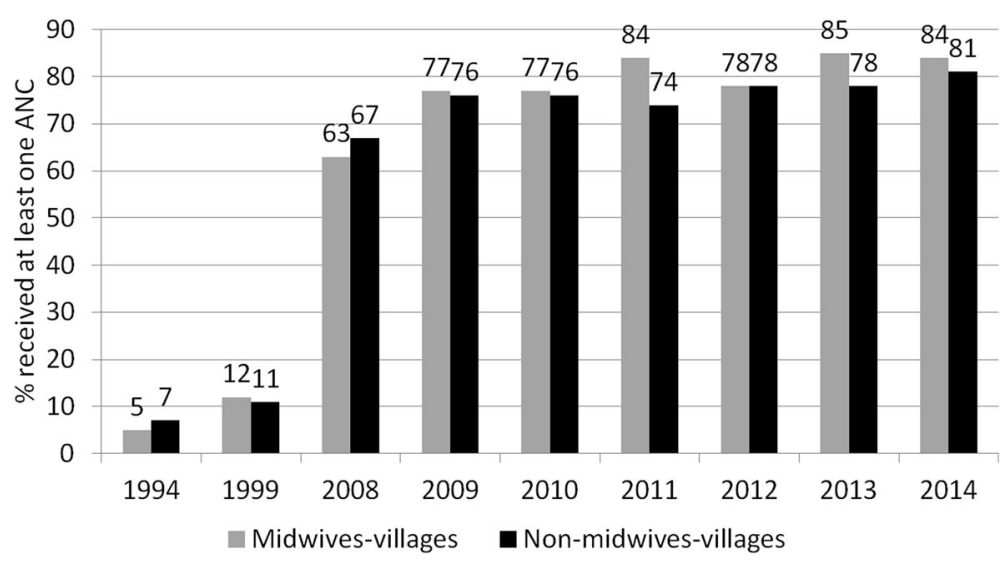

Fig. 5 Percentage of women received at least one ANC

services. Changes in some of the relevant indicators in the intervention and comparison areas are presented below.

\section{Infant mortality}

While infant mortality data were not available for the period 2000 to 2003, a larger decline in infant mortality rate was seen between 1999 and 2000 in intervention areas vs. comparison areas, during the most active period of the project. Subsequently, these gains were lost $[29,30]$ and overall there was no substantial difference in declines in infant mortality between 1999 and 2009 between intervention and comparison areas (Fig. 3).

\section{Immunization}

The percentage of fully immunized children in the intervention area increased substantially more from $47 \%$ in 1994 to $80 \%$ in 2014, compared to $61 \%$ in 1994 to $75 \%$ in 2014 in the comparison area (Fig. 4). The self-help program resulted in collective action supporting more regularly held and better utilized immunization services, by addressing negative attitudes towards immunization and mobilizing people to inform villagers about immunization sessions.

\section{Safe delivery}

Utilization of at least one ANC services increased in both intervention and comparison areas substantially from 5 and 7 \% in 1994 to 84 and $81 \%$ in 2014 (Fig. 5). In contrast, during the same time period while use of community midwives increased delivery by a skilled birth attendant (SBA) and facility deliveries more in intervention areas (3 to $43 \%$ SBA, 1 to $36 \%$ facility deliveries) than in comparison areas ( 4 to $32 \%$ SBA, 2 to $19 \%$ facility deliveries), substantial work remains to improve coverage in both areas (Figs. 6 and 7).

\section{Child nutrition}

An important focus of work carried out by SHOs was to monitor child nutrition and growth through village health posts and advise caregivers accordingly. As a part of data collection by the project, mid-upper arm circumference (MUAC) of children was collected in the HDSS area in 1994 and 1999 [31, 32]. The proportion of

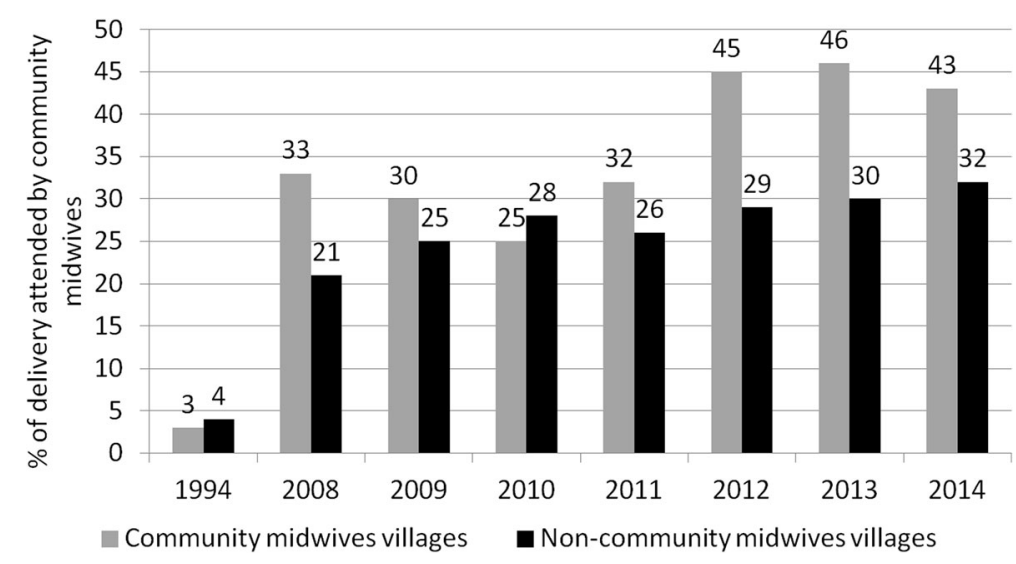

Fig. 6 Percentage of deliveries assisted by community midwives 


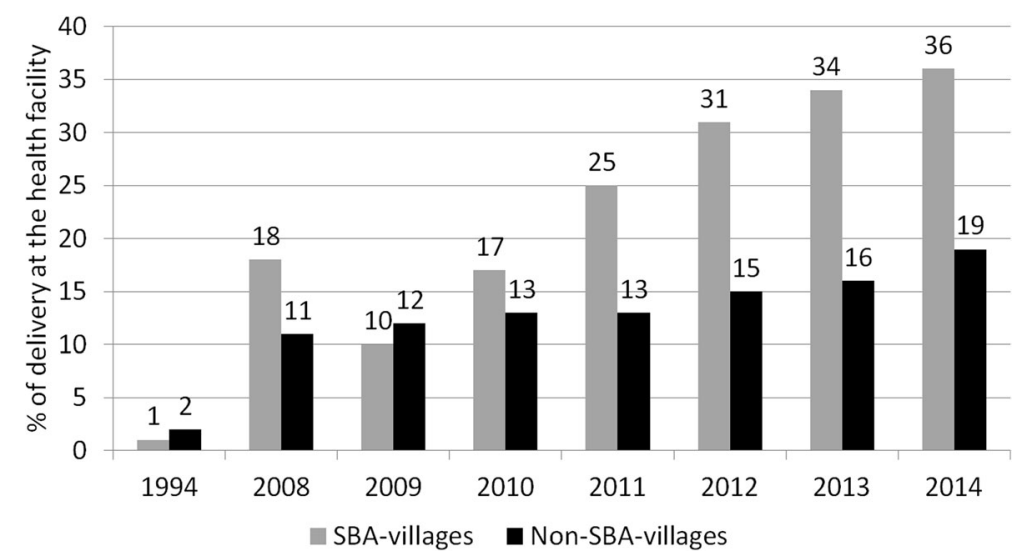

Fig. 7 Percentage of deliveries took place at health facility

severely malnourished children decreased in both the areas - although the decrease was higher in the intervention area compared to comparison area (Table 5).

\section{Sanitary latrine}

Information on sanitary latrines and health benefits of the use of sanitary latrines was shared in the meetings of the SHOs and to the villagers through the trained volunteers imparting health messages. This resulted in SHOs taking initiatives to install sanitary latrines in the community and some SHOs also established manufacturing units for construction components of sanitary latrines in the villages. Between 1994 and 2014, this resulted in a higher increase of households with sanitary latrines in the intervention area (18 to $58 \%$ ) compared to that in the comparison area (17 to $42 \%)$ (Fig. 8 ).

\section{Discussion}

The experience gained from supporting health promotion with self-help organizations following Verhagen's framework [19] and applying PRA has relevance for other similar settings in low-income countries. While initially, the health focus was thought to be challenging, but a substantial proportion of SHOs included health

Table 5 Distribution of MUAC of children aged 6-23 months, Chakaria, 1994 and 1999

\begin{tabular}{llllll}
\hline MUAC $(\mathrm{cm})$ & \multicolumn{2}{c}{ Intervention area } & & \multicolumn{2}{c}{ Comparison area } \\
\cline { 2 - 3 } \cline { 6 - 7 } \cline { 6 - 7 } & $1994(\%)$ & $1999(\%)$ & & $1994(\%)$ & $1999(\%)$ \\
\hline$<12.5$ (severely malnourished) & 38.9 & 22.0 & & 38.5 & 28.7 \\
$12.5-13.4$ & 29.1 & 38.6 & & 30.3 & 35.0 \\
$13.5+$ & 32.7 & 39.4 & & 31.2 & 36.3 \\
Mean & 12.3 & 13.2 & & 12.8 & 13.1 \\
Standard deviation & 1.2 & 1.2 & & 1.3 & 1.2 \\
Total number of children $(\mathrm{N})$ & 499 & 5025 & & 366 & 1682 \\
\hline
\end{tabular}

Source of data: Chakaria Health and Demographic Surveillance System onto their agendas. The proverbial sayings in Bangladesh that "Health is wealth" and "If money is lost, nothing is lost; but if health is lost, everything is lost" underline how health is linked to other livelihood concerns that are central to communities. Despite the successes realized, we also faced challenges in working with communities, which included lack of trust at the beginning, tensions related to including women, demands for material support and for curative services $[13,20]$. We conclude this paper by discussing how we faced each of these challenges and reflecting on issues of sustainability.

As mentioned, among the challenges faced, earning community trust was one of the first encountered by project staff. Initially, there was a strong anti-NGO sentiment prevailing in the area, leading project staff to consider deferring its training of volunteers. Instead the project decided to continue with the training plans, but moved the venue from isolated locations to villages where anybody could see and listen what the training was about. In addition to such measures supporting transparency of project actions, building trust required intensive work involving meeting key resource persons at their convenience and explaining the objectives of the project in clear terms, being respectful of community needs as much as possible, and demonstrating a listening mood. Confidence by community members in the project was bolstered by project staff demonstrating reasonableness in decision making and ensuring that what has been said by the project staff was followed through with. Trust was also facilitated by project staff emphasizing community solidarity by including everyone in the village irrespective of social and economic status.

Trust was an outcome of working against social divisions, but also key in facilitating inclusive participation. For example, SHOs initially only nominated men for training. After nearly a year into the participatory 


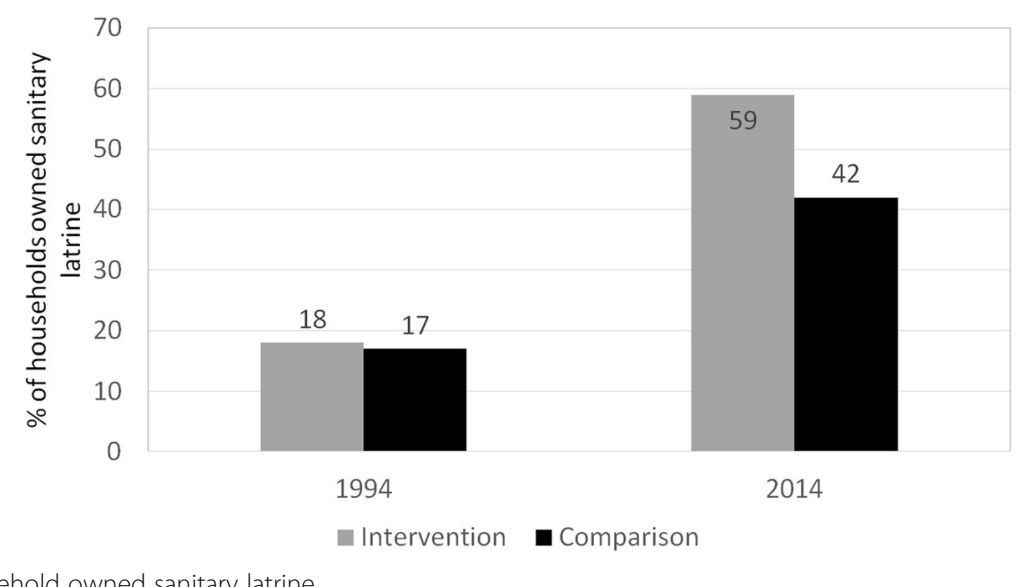

Fig. 8 Percentage of household owned sanitary latrine

planning, the situation was reviewed in SHO meetings on request from the project after having built strong relationships with SHOs. After project staff raising the issue, the SHO members who had exposure to the training programme and who had received feedback from the volunteers realised that the training on health, hygiene, water sanitation, and management of diarrhoea would be more beneficial if women were trained to serve as trainers who could reach other women in the community. This realization led to training of women, which was thought almost impossible at the beginning of the project.

The process of working together not only led to many health activities undertaken by the SHOs, but also the self-realization of community members of their own strength and capability. Moreover, the project played the role of a catalyst to realize the capability of the community for their own wellbeing without creating a dependency relationship between the community and the project. In doing so, the project contested the tendency by villagers of asking for material assistance from outside parties for things which could be managed with their own resources. In some instances, villagers expected project staff to lead activities in their villages -project staff were very particular in communicating that initiatives were not ready to be initiated until villagers were willing to lead them.

Demand for curative services was another challenge because the project was not designed to provide these services. A key learning has been the importance of flexibility in interactions with the SHOs/community members. No blueprint for the project other than the strategy depicted in Fig. 1 was pre-determined excepting the health focus. The project responded by expanding its mandate to support training of village level doctors and midwives, and in other instances by linking SHOs with other relevant agencies for work beyond project mandates.
This paper reflects on the experience of the project in supporting community capability over twenty years. A key feature of our work was our partnership with existing SHOs, instead of forming new groups or approaching community members directly. This helped mitigate the challenge of sustainability after phasing out of the project. As noted through DHSS data, to date some of the health indicators and health care utilization data indicate that positive effects still persist. The strongest of the sustained effects have been the functioning of village health posts, villagers' response to membership in the recently launched health insurance, and continuation of the project trained community midwives.

In the context of Bangladesh, community clinics, as the lowest level of health facilities, have sought local ownership by way of donating lands. Our experiences highlight that to succeed over the long term, engaging with communities, supporting their capabilities and ownership of community health requires a deeper engagement. Without involving the community in development activities, be it health or other, health planners and managers are unlikely to achieve their expected goals.

\section{Conclusion}

In conclusion, key learnings and recommendations for any initiatives of this kind to unlock community capability has to have the realization that there is no shortcut and that fixed blueprints are unlikely to work. The key is to listen to the community, showing respect to their concerns and jointly acting to tackle them. Wherever possible interventions should be in partnership with existing community organizations for it will not only increase the chances of success, but will also make the change lasting and will strengthen the local level organization of the people. Any 
investment on community created and owned organizations, empowers and equips the community to tackle future challenges.

\section{Abbreviations}

EPI: Expanded Program on Immunization; HDSS: Health and demographic surveillance system; icddr,b: International Centre for Diarrhoeal Disease Research, Bangladesh; MUAC: Mid-upper arm circumference; NGOs: Nongovernmental organizations; PAR: Participatory action research; PRA: Participatory Rural Appraisal; SHOs: Self-help organizations; SBA: Skilled birth attendant

\section{Acknowledgements}

The study was carried out at ICDDR,B. The work of this paper was possible with a grant of DFID through Johns Hopkins University under the DFID Research Consortium on Effective Service Delivery. The health and demographic data used in this paper were collected through Chakaria Health and Surveillance System which has been supported by ICDDR,B from its unrestricted funds. ICDDR,B's unrestricted funders included the Governments of Bangladesh, Canada, Sweden, and the United Kingdom. $I C D D R, B$ acknowledges the unrestricted support from the above countries for its research and infrastructure. The authors of this paper gratefully acknowledges the contribution of the villagers of Chakaria for their generous inputs, and the project research team for their assistance. Editorial assistance of Dr. Asha George and Dr. Kerry Scott is also gratefully acknowledged.

\section{Declarations}

This article has been published as part of BMC Health Services Research Volume 16 Supplement 7, 2016: Unlocking community capabilities across health systems across low and middle income countries. The full contents of the supplement are available online at http:// bmchealthservres.biomedcentral.com/articles/supplements/volume-16supplement-7.

\section{Funding}

The work of this paper was possible with a grant of DFID through Johns Hopkins University under the DFID Research Consortium on Effective Service Delivery. The health and demographic data used in this paper were collected through Chakaria Health and Surveillance System, which has been supported by ICDDR,B from its unrestricted funds. ICDDR,B's unrestricted funders included Government of Bangladesh, Canada, Sweden, and United Kingdom. Publication costs funded by the Future Health Systems Consortium (http://www.futurehealthsystems.org). Future Health Systems is funded by UK Aid from the UK Government.

\section{Availability of data and materials}

The authors confirm that all data underlying the findings are fully available without restriction. All data underlying the findings in this paper are freely available upon request subject to the adherence to icddr,b data sharing policy (www.icddrb.org/policies). The request for the data can be sent to hanifi@icddrb.org, co-investigator of the study.

\section{Authors' contributions}

AB SMAH SH conceived and designed the study. AB SMAH SH performed the experiments. AB SMAH SH analysed the data. AB SMAH SH wrote the paper. AB SMAH SH provided critical review, input and revision of the manuscript. All authors read and approved the final manuscript.

\section{Competing interests}

The authors declare that they have no competing interests.

\section{Consent for publication}

Not applicable.

\section{Ethical approval and consent to participate}

Ethical Review Committee of International Centre of Diarrhoeal Disease Research, Bangladesh provided approval for the study. Informed written and verbal consent was taken from all study participants, and confidentiality and anonymity were ensured as promised in dissemination and publication of findings.

\section{Author details}

${ }^{1}$ Partners in Population and Development, Dhaka, Bangladesh. ${ }^{2}$ Health Systems and Population Studies Division, International Centre for Diarrhoeal Disease Research, Bangladesh (icddr,b), Dhaka 1212, Bangladesh. ${ }^{3}$ Formerly of Health Systems and Population Studies Division, International Centre for Diarrhoeal Disease Research, Bangladesh (icddr,b), Dhaka 1212, Bangladesh.

Published: 15 November 2016

\section{References}

1. Rifkin SB. Paradigms lost: toward a new understanding of community participation in health programmes. Acta Trop. 1996;61 (2):79-92.

2. WHO. Community Participation: Advocacy and action. In: World Health Report. Geneva: Wrold Health Organization; 2004.

3. Chowdhury AMR, Aziz K, Bhuiya A. The Near miracle revisited: social science perspectives of the immunization programme in Bangladesh. Amsterdam: Het Spinhuis; 1999.

4. NIPORT. Bangladesh Dempgraphic and Health Survey, 2007. Dhaka: Mitra and Associates and MEASURE DHS, Macro International; 2009.

5. Bhuiya A, Yasmin F, BegUm F, Rob U. Community participation in health, family planning and development activities a review of international experiences. Bangladesh: The Population Council; 1996. p. 1-35.

6. Hossain SM, Bhuiya A, Khan AR, Uhaa I. Community development and its impact on health: South Asian experience. BMJ. 2004;328:830-3.

7. Chambers R. Ideas for development: reflecting Frwards' IDS working paper 238. Brighton: Institute of Development Studies; 2004.

8. Chambers R. The origins and practice of participatory rural appraisal. World Dev. 1994;22(7):953-69.

9. Bhuiya A, Yasmin F, Begum F, Rob U. Community participation in health, family planning and development programmes, international experiences. 1997.

10. Training and Research Support Centre (TARSC), and Ifakara Health Development Centre with EQUINET. Organizing People's Power for Health. 2006.

11. Rifkin SB. Lessons from community participation in health programmes: a review of the post Alma-Ata experience. Int Health. 2009;1(1):31-6.

12. George AS, Scott K, Mehra V, Sriram V. Synergies, strengths and challenges: findings on community capability from a systematic health systems research literature review. BMC Health Serv Res. Forthcoming.

13. Bhuiya A, Ribaux C, Eppler P. Community-led primary health care initiatives: lessons from a project in rural Bangladesh. In: Wyon, editor. Community based healthcare: lession from Bangladesh to Boston. RaJ: Management Science for Health; 2002.

14. BBS. Socioeconic and Demographic Report 2011. Dhaka: Bangladesh Bureau of Statistics; 2012

15. Bhuiya A, editor. Health for the rural masses: insights from Chakaria. Dhaka: ICDDR, B; 2009.

16. Bhuiya A, Hanifi S, Mahmood SS. Chakaria Health and Demographic Surveillance System: focusing on the poor and vulnerable. Socioeconomic, Health and Demographic Profile, 1999-2000. Dhaka: International Centre for Diarrhoeal Disease Research, Bangladesh (ICDDR,B); 2001

17. Boulter A, Lanzendorfer M, Yahiya M. Review of the Improvement of health through community development oriented programme in rural Bangladesh: Chakaria Community health project. Swiss Red Cross: Bern; 1994

18. Hanifi S, Sultana A, Mia MN, Hoque S, Mahmood SS, labal M, Bhuiya A. Chakaria Health and Demographic Surveillance System: focusing on the sustainable development goals. Dhaka: ICDDR, B; 2016.

19. Verhagen K, Cebemo O. Self-help promotion: A challenge to the NGO community. 1987.

20. Bhuiya A, Ribaux CA. Rethinking community participation: prospects of health initiatives by indigenous self-help organizations in rural Bangladesh. 1997

21. Ahmad A, Hossain M, Bose ML. Inequality in the access to secondary education and rural poverty in Bangladesh: An analysis of household and school level data. In: Workshop on Equity and Development in South Asia, India: 2005. 2005.

22. Bhuiya A, Hanifi SMA, Mahmood SS. Chakaria Health and Demographic Surveillance System: focusing on the poor and vulnerable, socioeconomic, health and demographic profile, 1999-2000. Dhaka: ICDDR,B; 2006. 
23. Hanifi SMA. Do participatory health interventions improve equity in early child health care? Experience from a project in Chakaria, Bangladesh. Umeå: International School of Public Health, Umeå University; 2003. MPH thesis.

24. Eppler P, Bhuiya A, Hossain M. A processed-oriented approach to the establishment of community-based village health posts. 1996.

25. Hossain M, Bhuiya A, Eppler P. Malaria Management practices and community response to malaria control measures in Chakaria. In: Fifth Annual Scientific Conference of ICDDR, B. Dhaka: ICDDR, B; 1996.

26. Iqbal M, Rashid S, Manzoor S, Hanifi A, Bhuiya A. Reaching the poor with performance based payment for safe delivery services in rural Bangladesh: potential of performance based payment. Medicus Mundi Schweiz. 2009; 112:37-42.

27. Bhuiya A, Hanifi S, Hossain M, Aziz A. Effects of an AIDS awareness campaign on knowledge about AIDS in a remote rural area of Bangladesh. Int Q Community Health Educ. 1999:19(1):51-63.

28. Wahed T, Rasheed S, Bhuiya A. Doctoring the village doctors: giving attention where it is due. 2013

29. Bhuiya A, Hanifi S, Mahmood S. Chakaria Health and Demographic Surveillance System: Focusing on the Poor and vulnerable, Demographic Profile, Family Planning Use and Safe Motherhood Practice-2005. Dhaka: ICDDR, B; 2007.

30. Hanifi S, Urni F, lqbal M, Hoque S, Bhuiya A. Chakaria Health and Demographic Surveillance System-Focusing on the Poor and Vulnerable: Demographic events, safe motherhood and water and sanitation practices2009. Dhaka: ICDDR, B; 2010.

31. Hanifi S, Hoque S, Moula A, Aziz RR. Study Area and the Population. In: Bhuiya A, editor. Health for the Rural Masses. Dhaka: ICDDR,B; 2009. p. 9.

32. Bhuiya A. Health knowedge and behavior in five unions of Chakaria. 1996.

\section{Submit your next manuscript to BioMed Central and we will help you at every step:}

- We accept pre-submission inquiries

- Our selector tool helps you to find the most relevant journal

- We provide round the clock customer support

- Convenient online submission

- Thorough peer review

- Inclusion in PubMed and all major indexing services

- Maximum visibility for your research

Submit your manuscript at www.biomedcentral.com/submit

C) Biomed Central 